\title{
BMJ Open Long-term trends and regional variations of hypertension incidence in China: a prospective cohort study from the China Health and Nutrition Survey, 1991-2015
}

\author{
Yunmei Luo (D) , ${ }^{1,2}$ Fan Xia, ${ }^{3}$ Xuexin Yu, ${ }^{4}$ Peiyi Li, ${ }^{1}$ Wenzhi Huang (D) , \\ Wei Zhang
}

To cite: Luo Y, Xia F, Yu X, et al. Long-term trends and regional variations of hypertension incidence in China: a prospective cohort study from the China Health and Nutrition Survey, 1991-2015. BMJ Open 2021;11:e042053. doi:10.1136/ bmjopen-2020-042053

- Prepublication history for this paper is available online. To view these files, please visit the journal online (http://dx.doi. org/10.1136/bmjopen-2020042053).

Received 29 June 2020 Revised 23 November 2020 Accepted 10 December 2020
D) Check for updates

(C) Author(s) (or their employer(s)) 2021. Re-use permitted under CC BY-NC. No commercial re-use. See rights and permissions. Published by BMJ.

For numbered affiliations see end of article.

Correspondence to Professor Wei Zhang; weizhanghx@163.com

\section{ABSTRACT}

Objective The aim is to explore the trends of hypertension incidence and regional variations in China from 1991 to 2015.

Design A dynamic prospective cohort study.

Setting China Health and Nutrition Survey 1991-2015.

Participants 12952 Chinese adults aged 18+ years.

Primary outcome measures Incident hypertension from 1993 to 2015.

Results Age-standardised hypertension incidence increased from 40.8 per 1000 person-years $(95 \% \mathrm{Cl} 38.3$ to 43.4 ) between 1993 and 1997 to 48.6 (95\% Cl 46.1 to 51.0) between 2011 and 2015. The increasing trends were further supported by results from subsequent extended Cox proportional hazard model. In addition, results from the modelling analysis showed that individuals in eastern, central and northeastern China had greater risks of hypertension occurrence in comparison with their counterparts in western China.

Conclusion Hypertension incidence increased during the study period. The growth called for more attention on the health education and health promotion of individuals with great risks.

\section{INTRODUCTION}

Along with ageing population, noncommunicable chronic diseases, particularly stroke and ischaemic heart disease, have led to great burden of disease, deaths and years of life lost in both developed and developing countries. ${ }^{12}$ Connected closely with various cardiovascular diseases, ${ }^{34}$ high systolic blood pressure (SBP) was ranked as the leading risk factor of risk-attributable disability-adjusted life-years (DALYs) among selected 195 countries and territories. ${ }^{5}$ For instance, high SBP accounted for 2.54 million deaths and more than $5 \%$ of DALYs in China in $2017 .^{6}$

Existing evidence has confirmed a worldwide high prevalence of hypertension. ${ }^{4-6}$ Countries, such as Singapore ${ }^{6}$ and Korea, ${ }^{7}$
Strengths and limitations of this study

- The dynamic cohort study design employed individuals from diverse social and geographic contexts, which enabled us to depict the long-term trends of hypertension incidence and regional disparities in the context of China's rapid social development and population ageing.

- We adopted both self-reported health outcomes and objective outcomes from physical tests, which to some extent minimised the recall bias and underestimation in underserved areas.

- We did not employ a national representative sample and did not include individuals from all provinces in China, which undermined the representation of our findings.

- Guidelines recommend to identify hypertension cases by using blood pressure values that are measured in different days, while individuals' blood pressure data in the China Health and Nutrition Survey were collected on the same day, which may lead to unavoidable bias.

- We did not distinguish the grade of hypertension, and future research is necessary.

had a significant proportion of individuals with hypertension. Likewise, with the extended life expectancy, ${ }^{8}$ changes in lifestyle behaviours, ${ }^{9}$ and rapid urbanisation, ${ }^{10}$ developing countries, such as China, experienced a substantial increase in the prevalence of hypertension, ranging from $13.6 \%$ in 1991 to $27.9 \%$ in $2015 .^{11}$

Although the increasing prevalence of hypertension provided critical information for public health practice and disease control programmes, it could not accurately depict the epidaemiological transition as the incidence measure. ${ }^{12}$ Prior studies have indicated that the increasing prevalence could coexist with the decreasing incidence in the context 
of healthy ageing. ${ }^{13}$ For evidence-based health-promoting initiatives, empirical research on hypertension incidence is warranted.

However, research on the long-term trends of the incidence of hypertension from China is scare and relatively outdated. ${ }^{1415}$ This is an important knowledge gap because developing countries are experiencing unprecedented social development. Up-to-date information among developing countries could greatly contribute to depict global epidaemiological transitions. Moreover, regional disparities are a major health concern in China as a result of inequitable socioeconomic development and healthcare resource distribution, ${ }^{16-18}$ while the existing research provides insufficient information regarding the regional disparities in the hypertension incidence. ${ }^{19-21}$

Hence, this study aims to explore the long-term trends of hypertension incidence among Chinese from diverse social and geographic contexts. In addition, we are particularly interested in regional variations while taking the individual-level risk factors into account.

\section{METHODS}

\section{Data source}

The present study derived data from the China Health and Nutrition Survey (CHNS). CHNS has been collaboratively conducted by Carolina Population Center at the University of North Carolina at Chapel Hill and the National Institute for Nutrition and Health (former National Institute of Nutrition and Food Safety) at the Chinese Center for Disease Control and Prevention. Initiated in 1989, CHNS consisted of 10-wave data in 1989, 1991, 1993, 1997, 2000, 2004, 2006, 2009, 2011 and 2015, respectively. Overall, CHNS employed a multistage random cluster method to draw the study sample, which included over 30000 individuals from three provincial-level cities and 12 provinces. Individuals in the survey came from diverse social, geographic and cultural contexts. CHNS employed face-to-face questionnaire interviews to collect data, and the physical health examinations were conducted by well-trained investigators. Information regarding survey design, data collection, and quality control could be retrieved from the cohort profile. ${ }^{22}$

\section{Study design and exclusion criteria}

The present study employed a dynamic cohort study design as not all individuals entered the cohort at the same time. To evaluate the long-term trends of hypertension incidence, we excluded individuals (a) without individual ID and community ID; (b) aged under 18 years because of the low incidence of hypertension among children and teenagers; (c) with hypertension in his/her first investigation; (d) with only one observation or only one record of hypertension status and (e) who were pregnant during the study period to exclude gestational hypertension. Furthermore, we excluded observations after the diagnosis of hypertension (figure 1). As death data were not available in CHNS, censoring could be for death or lost to follow-up.

\section{Exposures}

The primary exposure variable of this study were the timing of entering the cohort and geographic regions. For modelling analyses, it was not feasible to treat the waves as continuous variables, and therefore, we respectively grouped the individuals entering the cohort from (a) 1991, 1993 and 1997; (b) 2000, 2004, 2006 and 2009 and (c) 2011 and 2015. In this case, two dummies were introduced in the model with individuals from 1991 to 1997 as the reference group.

Geographic regions were defined according to the bulletin of the National Bureau of Statistics of China. Specifically, we grouped individuals from (a) Beijing, Shanghai, Jiangsu Province, Zhejiang Province and Shandong Province as eastern China; (b) Henan Province, Hubei Province and Hunan Province as central China; (c) Liaoning Province and Heilongjiang Province as northeastern China and (d) Yunnan Province, Guangxi Zhuang Autonomous Region, Guizhou Province, Chongqing and Shanxi Province as western China.

\section{Outcomes}

We included incidence of hypertension as the primary outcome. First, we adopted self-reported hypertension, which was derived from the answer to the question, 'Has a doctor ever told you that you had high blood pressure?'. If individuals self-reported no hypertension history, the outcomes would be further supplemented by the blood pressure tests to avoid the recall bias and underestimation from self-reported measures. According to the criteria of the 2018 Clinical Guideline in China and the 2018 ESC/ ESH HTN Guideline, ${ }^{23}$ hypertension was confirmed with the $\mathrm{SBP} \geq 140 \mathrm{~mm} \mathrm{Hg}$ or with the diastolic blood pressure $\geq 90 \mathrm{~mm} \mathrm{Hg}$. To guarantee the accuracy of the tests, the blood pressure was detected in triplicate by professional health workers on the same day.

\section{Covariates}

To adjust for variations in baseline characteristics, we introduced several confounding factors that may influence the occurrence of hypertension. These factors included urban versus rural settings, sociodemographic characteristics (age, sex, race, marital status, educational attainment and employment status) and lifestyle attributes (body mass index (BMI), smoking behaviours, alcohol consumption and physical activity). ${ }^{15} 24$

\section{Statistical analysis}

First, we performed $\chi^{2}$ tests and Kruskal-Wallis rank-sum tests to evaluate variations in baseline characteristics over time. Second, we calculated the crude incidence of hypertension as below ${ }^{25}$ :

$$
\text { Incidence }=\frac{\text { number of new hypertension cases }}{\text { total person }- \text { years at risk }}
$$




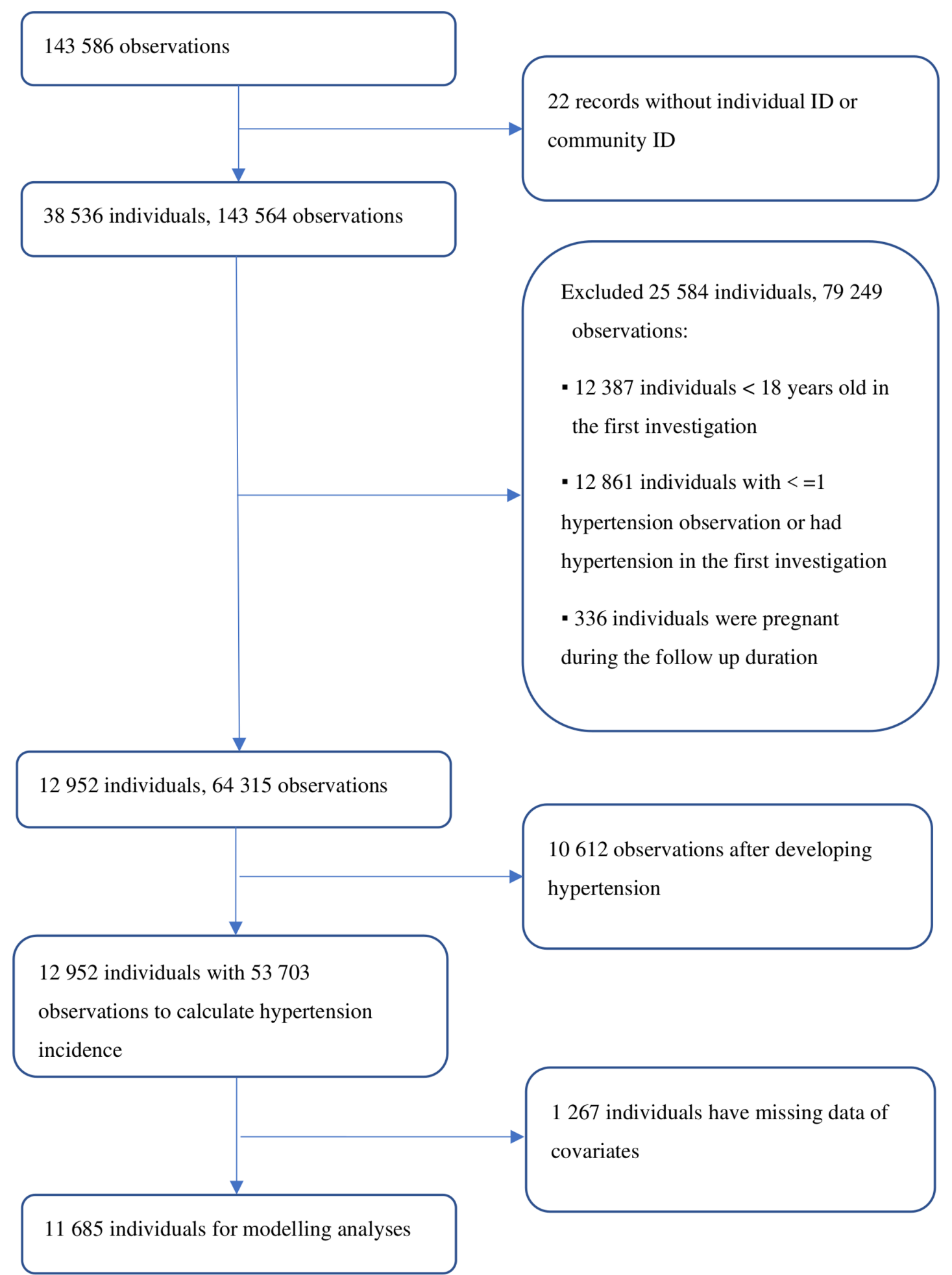

Figure 1 Flowchart showing the selection of the subjects who were included in the final analysis of hypertension incidence in China, with covariate information missing rate of $9.78 \%$.

The 'person-years at risk' is the period from the first hypertension-free year to the year when the subsequent hypertension is confirmed. In addition, we conducted direct standardisation to calculate the age-standardised incidence of hypertension by using the study sample from wave 2011 to wave 2015 as the standard population. Subgroup analyses were conducted by sex.
To further evaluate the long-term trends and geographic variations of incident hypertension, we performed an extended Cox proportional hazard model while including all covariates to control for baseline variations. Because the effect of age did not conform to the proportional hazard assumption, we performed a time-dependent Cox regression model with age as a time-dependent variable. 
Table 1 Observation distribution of study sample from 1991 to 2015

\begin{tabular}{lrrrrrrrrr}
\hline Wave & $\mathbf{1 9 9 1}$ & $\mathbf{1 9 9 3}$ & $\mathbf{1 9 9 7}$ & $\mathbf{2 0 0 0}$ & $\mathbf{2 0 0 4}$ & $\mathbf{2 0 0 6}$ & $\mathbf{2 0 0 9}$ & $\mathbf{2 0 1 1}$ & $\mathbf{2 0 1 5}$ \\
\hline 1989 & & & & & & & & & \\
1991 & 5938 & & & & & & & & \\
1993 & 5166 & 677 & & & & & & & \\
1997 & 3313 & 485 & 1691 & & & & & \\
2000 & 2658 & 335 & 1451 & 1009 & & & & \\
2004 & 2050 & 234 & 1037 & 813 & 837 & & & \\
2006 & 1722 & 188 & 865 & 642 & 684 & 376 & & \\
2009 & 1378 & 142 & 385 & 398 & 413 & 302 & 692 & & \\
2011 & 1200 & 114 & 329 & 335 & 359 & 216 & 630 & 1732 & \\
2015 & 912 & 86 & 250 & 236 & 231 & 152 & 353 & 1732 & 0 \\
\hline
\end{tabular}

As for sensitivity analyses, we construct the multi-level Poisson regression indicating similar findings.

Data analyses were performed with Stata V.15.0 (StataCorp, Texas, USA). A two-tailed p value of less than 0.05 was considered statistical significance.

\section{Patient and public involvement}

Patients and the public were not involved in the research.

\section{RESULTS}

\section{Study population}

The CHNS consisted of data of 38558 individuals with 143586 observations from 1989 to 2015, and the present study only included 12952 individuals from 1991 to 2015 after sample selection (figure 1). Table 1 presents the distribution of observations from included individuals during the study period. For example, 5938 individuals entered the cohort in 1991, with only 912 followed-up in 2015 (table 1). Among the 12952 participants, 5119 of them developed hypertension during the follow-up period.

Table 2 presents the baseline characteristics of the study sample. Overall, variations existed in all baseline characteristics. Newly recruited individuals were older $(p<0.001)$ and well educated $(p<0.001)$. They were more likely to be obese $(p<0.001)$, Han $(p<0.001)$ and men $(p<0.001)$, and they were less likely to be smokers $(p<0.001)$, employed $(\mathrm{p}<0.001)$ and physically active $(\mathrm{p}<0.001)$.

\section{Crude and age-standardised incidence}

Table 3 presents the crude and age-standardised hypertension incidence during the study period. For the calculation of hypertension incidence, we employed the full sample of 12952 individuals with 53703 observations. The age-standardised incidence of hypertension witnessed a significant increase, ranging from 40.8 per 1000 person-years (95\% CI 38.3 to 43.4) between 1993 and 1997 to 48.6 per 1000 person-years (95\% CI 46.1 to $51.0)$ between 2011 and 2015. The increasing pattern was also exhibited among men (1993-1997: 46.2, 95\% CI 42.1 to 50.4 ; 2011-2015: $55.7,95 \%$ CI 51.7 to 59.7$)$ and women
(1993-1997: 36.5, 95\% CI 33.2 to 39.7; 2011-2015: 43.3, $95 \%$ CI 40.2 to 46.3$)$.

\section{Extended COX proportional hazard analysis}

For the modelling analysis, we included 11685 individuals without missing data (missing rate, 9.78\%). Among the identified cases, the duration from free of hypertension to incident hypertension ranged from 2 to 24 years, with a median of 9 years.

Table 4 presents results from extended Cox proportional hazard analysis while taking variations in baseline characteristics into account. First, the increasing trends of hypertension incidence were robust, as suggested by the modelling results. Specifically, individuals entering the cohort from 2000 to 2009 (ajusted Hazard Ratio (aHR) $=1.10,95 \%$ CI 1.01 to 1.21) and those from 2011 to 2015 (aHR=1.19, 95\% CI 1.04 to 1.37 ) had a higher risk of hypertension in comparison with individuals entering the cohort from 1991 to 1997. With reference to regional variations, individuals in central $(\mathrm{aHR}=1.26,95 \%$ CI 1.16 to 1.37$)$, northeastern $(\mathrm{aHR}=1.56,95 \% \mathrm{CI} 1.41$ to 1.72$)$ and eastern China (aHR=1.48, 95\% CI 1.36 to 1.63 ), respectively, had a higher risk of hypertension occurrence relative to their counterparts in western China.

In addition, there existed no urban-rural differences in developing hypertension (table 4). Risks of incident hypertension increased with age, BMI and alcohol consumption, while it was negatively associated with educational attainment. Women had a lower risk of incident hypertension compared with men $(\mathrm{aHR}=0.81,95 \%$ CI 0.74 to $0.88)$. Relative to those without a job, employees had a lower risk of developing hypertension $(\mathrm{aHR}=0.90,95 \% \mathrm{CI}$ 0.82 to 0.99 ). Han individuals were significantly associated with a higher risk $(\mathrm{aHR}=1.11,95 \%$ CI 1.01 to 1.23$)$ relative to the minority.

\section{DISCUSSION}

By employing a study sample of 12925 individuals from diverse social and geographic contexts, we found the agestandardised incidence of hypertension increased during 
Table 2 Baseline characteristics of study individuals, $n(\%)^{*}$

\begin{tabular}{|c|c|c|c|c|}
\hline \multirow[b]{2}{*}{ Characteristic } & \multicolumn{3}{|c|}{ Time entering the cohort } & \multirow[b]{2}{*}{$P$ value } \\
\hline & 1991-1997 & 2000-2009 & 2011-2015 & \\
\hline \multicolumn{5}{|l|}{ Region } \\
\hline Central & 2817 (33.92) & $800(27.45)$ & $85(4.91)$ & \multirow{2}{*}{$<0.001$} \\
\hline Northeastern & $1288(15.51)$ & $794(27.25)$ & $83(4.79)$ & \\
\hline \multicolumn{5}{|l|}{ Urban-rural } \\
\hline Rural & $5616(67.61)$ & $1717(58.92)$ & $777(44.86)$ & \multirow[t]{2}{*}{$<0.001$} \\
\hline Urban & 2690 (32.39) & $1197(41.08)$ & $955(55.14)$ & \\
\hline \multicolumn{5}{|l|}{ Age (years) } \\
\hline $50-59$ & $1004(12.09)$ & 405 (13.90) & $456(26.33)$ & \multirow{2}{*}{$<0.001$} \\
\hline$\geq 60$ & $794(9.56)$ & $339(11.63)$ & $286(16.51)$ & \\
\hline \multicolumn{5}{|l|}{ Sex } \\
\hline Male & 3986 (47.99) & 1168 (40.08) & $736(42.49)$ & \multirow[t]{2}{*}{$<0.001$} \\
\hline Female & $4320(52.01)$ & $1746(59.92)$ & $996(57.51)$ & \\
\hline \multicolumn{5}{|l|}{$\mathrm{BMI}\left(\mathrm{kg} / \mathrm{m}^{2}\right)$} \\
\hline$<18.5$ & $763(9.27)$ & $191(6.60)$ & $60(3.46)$ & \multirow[t]{3}{*}{$<0.001$} \\
\hline $18.5-23.9$ & $6012(73.07)$ & $1776(61.35)$ & $955(55.14)$ & \\
\hline $24.0-27.9$ & $1238(15.05)$ & $760(26.25)$ & $545(31.47)$ & \\
\hline Married & $7098(85.71)$ & $2545(88.18)$ & $1531(88.86)$ & $<0.001$ \\
\hline \multicolumn{5}{|l|}{ Education attainment } \\
\hline Primary school and below & $4416(53.81)$ & $741(26.43)$ & $410(23.73)$ & \multirow[t]{4}{*}{$<0.001$} \\
\hline Middle school & 2377 (28.97) & $1103(39.34)$ & $457(26.45)$ & \\
\hline High school or equivalent & $1240(15.11)$ & $742(26.46)$ & $472(27.31)$ & \\
\hline College and above & $173(2.11)$ & $218(7.77)$ & $389(22.51)$ & \\
\hline \multicolumn{5}{|l|}{ Employed } \\
\hline No & $1145(13.85)$ & $1044(35.95)$ & $716(41.34)$ & \multirow[t]{2}{*}{$<0.001$} \\
\hline Yes & $7121(86.15)$ & $1860(64.05)$ & $1016(58.66)$ & \\
\hline \multicolumn{5}{|l|}{ Smoking history } \\
\hline Never or smoking cessation & $5300(64.72)$ & $2163(74.97)$ & $1326(77.18)$ & \multirow[t]{3}{*}{$<0.001$} \\
\hline Current smoker, cigarettes <20/day & $1481(18.09)$ & $370(12.82)$ & $205(11.93)$ & \\
\hline Current smoker, cigarettes $\geq 20 /$ day & $1408(17.19)$ & $352(12.20)$ & $187(10.88)$ & \\
\hline \multicolumn{5}{|l|}{ Alcohol consumption } \\
\hline Never & $5042(61.82)$ & 2037 (70.93) & $1116(65.03)$ & $<0.001$ \\
\hline Not more than once per month & $469(5.75)$ & $102(3.55)$ & $144(8.39)$ & \\
\hline 1-3 times per month & $661(8.10)$ & $173(6.02)$ & $127(7.40)$ & \\
\hline
\end{tabular}


Table 2 Continued

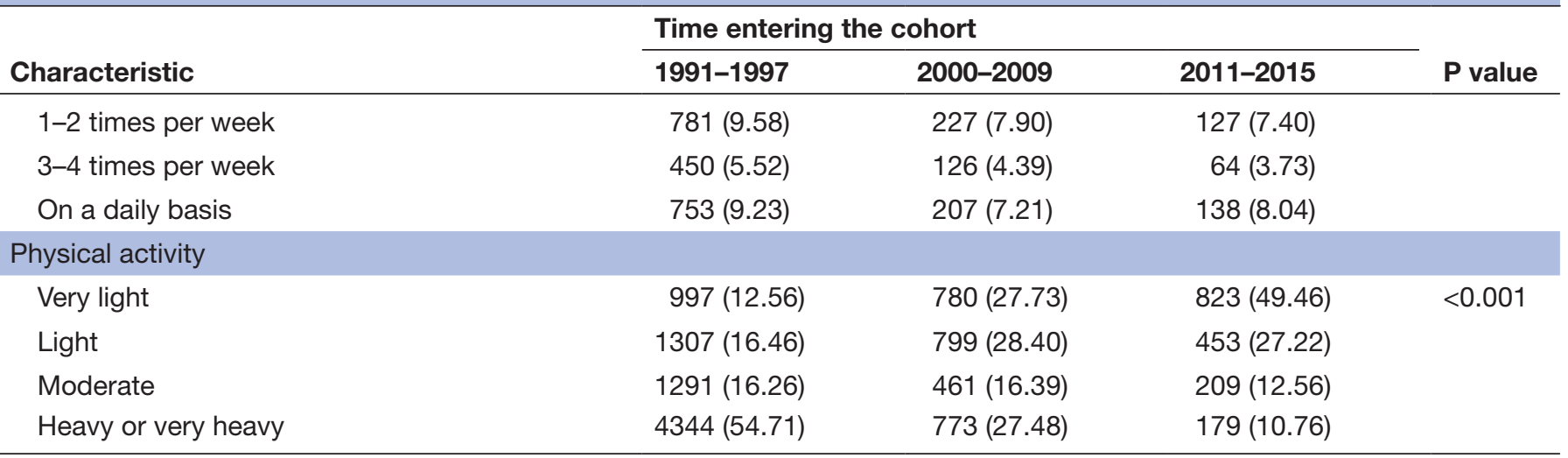

*Overall, we included 11685 individuals in the modelling analyses after excluding 97 individuals without body mass index, 74 without race, 62 without marital status, 214 without educational attainment, 50 without employment status, 160 without smoking history, 208 without alcohol consumption and 449 without physical activity. (Missing rate $9.78 \%$.)

the study period. The increasing pattern remained even after controlling for variations in baseline characteristics. Furthermore, we found that individuals in economically developed eastern, central and northeastern China had greater risks of incident hypertension in comparison with those in western China.

Instead of focusing on the incidence measure, the vast majority of prior studies focused on the prevalence measure. For example, one of the previous studies in China indicated that the prevalence of hypertension rose substantially from $13.6 \%$ in 1991 to $27.9 \%$ in $2015 .{ }^{11}$ The findings were further supplemented by results from $\mathrm{Lu} e t$ $a l$, which suggested a higher prevalence of hypertension among those aged between 35 and 75 years $(44.7 \%){ }^{26}$ Compared with these earlier studies, our focus on the incidence measure provided a more accurate reflection of the epidaemiologic transition of hypertension in China. ${ }^{12}$ Our findings updated the trends of hypertension incidence in comparison with that from Liang et al, which indicated a similar pattern from 1991 to $2009 .{ }^{15}$ Even though hypertension incidence appeared to vary across countries, ${ }^{27-29}$ the comparison is untenable because we adopted different standard populations. Further empirical research across countries is warranted.

With the rapid economic development, people often change their dietary patterns from light diet to high salt and fat diet along with a secondary lifestyle..$^{30}$ These changes would significantly impact the prevalence and control of hypertension in China. ${ }^{30}$ In addition, due to data limitation, we were unable to introduce several potential risks factors, such as sodium intake or dietary pattern, parental history, psychological status, ambient air pollutants, working hours and household income. ${ }^{31-34}$ These factors may explain the residual time effects in the model.

Although existing evidence on the regional disparities of hypertension incidence is scant, prior research indicates that central, northeastern and eastern China had a higher prevalence of hypertension compared

\begin{tabular}{|c|c|c|c|c|}
\hline Incidence & 1991 & 1993-1997 & 2000-2009 & 2011-2015 \\
\hline \multicolumn{5}{|l|}{ Total } \\
\hline Case (person-year) & - & $1114(35486)$ & 2571 (70 575) & 1434 (29 492) \\
\hline Crude incidence $(95 \% \mathrm{Cl})$ & - & 31.3 (29.6 to 33.2 ) & 36.4 (35.0 to 37.8$)$ & 48.6 (46.1 to 51.2$)$ \\
\hline Age-standardised incidence $(95 \% \mathrm{Cl})^{\star}$ & - & 40.8 (38.3 to 43.4$)$ & 41.5 (39.9 to 43.2$)$ & 48.6 (46.1 to 51.0$)$ \\
\hline \multicolumn{5}{|l|}{ Male } \\
\hline Case (person-year) & - & 594 (17 530) & 1292 (32 524) & $699(12532)$ \\
\hline Crude incidence $(95 \% \mathrm{Cl})$ & - & 33.8 (31.2 to 36.7$)$ & 39.7 (37.6 to 41.9$)$ & 55.7 (51.7 to 60.0$)$ \\
\hline Age-standardised incidence $(95 \% \mathrm{Cl})^{\star}$ & - & 46.2 (42.1 to 50.4$)$ & 45.7 (43.0 to 48.3$)$ & 55.7 (51.7 to 59.7$)$ \\
\hline \multicolumn{5}{|l|}{ Female } \\
\hline Case (person-year) & - & 520 (17 956) & 1279 (38 051) & 735 (16 960) \\
\hline Crude incidence $(95 \% \mathrm{Cl})$ & - & 28.9 (26.5 to 31.5$)$ & 33.6 (31.8 to 35.5$)$ & 43.3 (40.3 to 46.5$)$ \\
\hline Age-standardised incidence $(95 \% \mathrm{Cl})^{*}$ & - & 36.5 (33.2 to 39.7$)$ & 38.0 (35.9 to 40.1$)$ & 43.3 (40.2 to 46.3$)$ \\
\hline
\end{tabular}

*Age-standardised incidence was calculated using the study sample in 2011-2015 as the standard population. 
Table 4 Extended Cox proportional hazard analysis of hypertension incidence

\begin{tabular}{|c|c|c|}
\hline Characteristic & aHR $(95 \% \mathrm{Cl})$ & $P$ value \\
\hline \multicolumn{3}{|l|}{ Timing of entering the cohort } \\
\hline 1991-1997 & Ref. & \\
\hline 2000-2009 & $1.10(1.01$ to 1.21$)$ & 0.025 \\
\hline 2011-2015 & 1.19 (1.04 to 1.37$)$ & 0.010 \\
\hline \multicolumn{3}{|l|}{ Geographic region } \\
\hline Western & Ref. & \\
\hline Central & 1.26 (1.16 to 1.37$)$ & $<0.001$ \\
\hline Northeastern & 1.56 (1.41 to 1.72$)$ & $<0.001$ \\
\hline Eastern & 1.48 (1.36 to 1.63$)$ & $<0.001$ \\
\hline Urban (vs rural) & 0.94 (0.88 to 1.01$)$ & 0.109 \\
\hline \multicolumn{3}{|l|}{$\operatorname{Age}^{*}$} \\
\hline $18-29$ & Ref. & \\
\hline 30-39 & $1.93(1.41$ to 2.65$)$ & $<0.001$ \\
\hline $40-49$ & 3.99 (2.93 to 5.43$)$ & $<0.001$ \\
\hline $50-59$ & 5.16 (3.74 to 7.12$)$ & $<0.001$ \\
\hline$\geq 60$ & 9.11 (6.50 to 12.77$)$ & $<0.001$ \\
\hline Female (vs male) & 0.81 (0.74 to 0.88$)$ & $<0.001$ \\
\hline \multicolumn{3}{|l|}{ Body mass index $\left(\mathrm{kg} / \mathrm{m}^{2}\right)$} \\
\hline$<18.5$ & Ref. & \\
\hline $18.5-23.9$ & 1.31 (1.16 to 1.48$)$ & $<0.001$ \\
\hline $24.0-27.9$ & 2.07 (1.81 to 2.36$)$ & $<0.001$ \\
\hline$\geq 28$ & 2.82 (2.37 to 3.34$)$ & $<0.001$ \\
\hline Race (Han vs others) & 1.11 (1.01 to 1.23$)$ & 0.032 \\
\hline Married (vs others) & 0.92 (0.83 to 1.02$)$ & 0.149 \\
\hline \multicolumn{3}{|l|}{ Educational attainment } \\
\hline Primary school and below & Ref. & \\
\hline Middle school & 0.91 (0.84 to 0.99) & 0.020 \\
\hline High school or equivalent & 0.86 (0.77 to 0.95$)$ & 0.002 \\
\hline College and above & $0.82(0.68$ to 0.98$)$ & 0.033 \\
\hline Employed (yes vs no) & 0.90 (0.82 to 0.99$)$ & 0.036 \\
\hline \multicolumn{3}{|l|}{ Smoking } \\
\hline $\begin{array}{l}\text { Never or smoking } \\
\text { cessation }\end{array}$ & Ref. & \\
\hline $\begin{array}{l}\text { Current smoker, cigarettes } \\
<20 / \text { day }\end{array}$ & 0.98 (0.89 to 1.07$)$ & 0.752 \\
\hline $\begin{array}{l}\text { Current smoker, cigarettes } \\
\geq 20 / \text { day }\end{array}$ & 1.05 (0.96 to 1.16$)$ & 0.237 \\
\hline \multicolumn{3}{|l|}{ Alcohol consumption } \\
\hline Never & Ref. & \\
\hline $\begin{array}{l}\text { Not more than once per } \\
\text { month }\end{array}$ & 0.89 (0.78 to 1.03$)$ & 0.125 \\
\hline 1-3 times per month & 1.17 (1.04 to 1.32$)$ & 0.006 \\
\hline 1-2 times per week & 1.00 (0.89 to 1.12$)$ & 0.963 \\
\hline 3-4 times per week & 1.05 (0.92 to 1.21$)$ & 0.412 \\
\hline On a daily basis & 1.18 (1.06 to 1.31$)$ & 0.002 \\
\hline
\end{tabular}

Continued
Table 4 Continued

\begin{tabular}{lll}
\hline Characteristic & aHR $(95 \% \mathbf{C l})$ & P value \\
\hline Very light & Ref. & \\
Light & $0.92(0.83$ to 1.02$)$ & 0.154 \\
Moderate & $0.99(0.88$ to 1.11$)$ & 0.930 \\
Heavy and very heavy & $0.91(0.82$ to 1.02$)$ & 0.118 \\
\hline
\end{tabular}

${ }^{\star}$ Estimated time effect of age, $p<0.001$.

with western China, ${ }^{35}$ which is in line with our findings. In sharp contrast, prior investigators have noted that northeastern and central China had lower allcause mortality rates relative to western China. ${ }^{36}$ These findings appear to suggest that individuals in China's economically developed regions are experiencing extended life expectancy with relatively unhealthy ageing. ${ }^{12}$ However, one should be aware of the possibility that although individuals in western China had lower risks of hypertension compared with the other three regions, local public awareness and timely treatment could be a challenging issue.

Differed from previous studies, ${ }^{15} 37$ no urban-rural disparities were observed in the present study. This may be a result of the narrowing gap of lifestyle between rural and urban residents. With the rapid economic development and urbanisation in the past few decades, the lifestyle and dietary pattern of rural residents are approaching to those of their counterparts in urban China. ${ }^{910}$ This possibility has been further supported by the fact that the prevalence of hypertension in rural China exceeded that of urban China in $2015 .^{26}$ Taking into account the lower treatment rate and insufficient awareness among rural residents, ${ }^{38}$ one should direct more attention to rural China.

Moreover, we found that smoking history was not associated with incident hypertension. The effect of smoking on the development of the chronic disease is unclear and appears to differ across life courses. ${ }^{39-41}$ Prior research based on Korean has found a J-shaped association between physical activity and incident hypertension, ${ }^{42}$ while the present study on Chinese did not observe a similar association, which is in line with findings based on Japanese. ${ }^{43}$ The effect of physical activity on the development of hypertension seems to be controversial and varies across countries. Further analyses are warranted.

Consistent with the previous studies, ${ }^{44-47}$ several risk factors, including age, gender, educational attainment, race, alcohol consumption and BMI, were confirmed by our analyses. The growing incidence of hypertension emphasises the early prevention, education, detection and management for hypertension. ${ }^{48}$ Mentoring aforementioned lifestyle behaviours, such as alcohol consumption, may be helpful to constrain the hypertension incidence. ${ }^{49}$ Public health and lifestyle interventions targeting high-risk individuals, such as older adults, men and obese population, hold promise. 


\section{Conclusion}

Hypertension incidence increased during the study period. Individuals in eastern, central and northeastern China had greater risks of hypertension in comparison with their counterparts in western China. Risks of incident hypertension increased with age, BMI and alcohol consumption but negatively associated with educational attainment. The growth of hypertension incidence calls for more attention on the health education and health promotion of individuals with great risks.

\section{Strengths and limitations of this study}

The present study has two major strengths. First, the dynamic cohort study design employed individuals from diverse social and geographic contexts, which enabled us to depict the long-term trends of hypertension incidence and regional disparities in the context of China's rapid social development and population ageing. In addition, we adopted both self-reported health outcomes and objective outcomes from physical tests, which avoided the recall bias and underestimation in underserved areas.

Nevertheless, this study is subject to several limitations. First, we did not employ a national representative sample and did not include individuals from all provinces in China, which undermined the representation of our findings. As a community-based survey, the CHNS excluded institutionalised individuals, which further diminished the representation of our findings among Chinese. Third, 2018 Clinical Guideline in China recommend to identify hypertension cases by using blood pressure values that are measured in different days, ${ }^{23}$ while individuals' blood pressure data in the CHNS were collected on the same day in the CHNS, leading to unavoidable bias. Last, we did not distinguish the grade of hypertension, and future research is necessary.

\section{Author affiliations}

${ }^{1}$ Institute of Hospital Management, West China Hospital, Sichuan University, Chengdu, Sichuan, China

${ }^{2}$ West China Medical Publishers, West China Hospital, Sichuan University, Chngdu, Sichuan, China

${ }^{3}$ Department of Neurosurgery, West China Hospital, Sichuan University, Chengdu, Sichuan, China

${ }^{4}$ West China Biomedical Big Data Center, West China Hospital, Sichuan University, Chengdu, Sichuan, China

${ }^{5}$ Department of Infection Control, West China Hospital, Sichuan University, Chengdu, Sichuan, China

Correction notice This article has been corrected since it first published. The provenance and peer review statement has been included.

Acknowledgements We thank the National Institute for Nutrition and Health, China Center for Disease Control and Prevention, Carolina Population Center (P2C HD050924, T32 HD007168), the University of North Carolina at Chapel Hill, the NIH (R01-HD30880, DK056350, R24 HD050924 and R01-HD38700) and the NIH Fogarty International Center (D43 TW009077 and D43 TW007709) for financial support for the CHNS data collection and analysis files from 1989 to 2015 and future surveys, and the China-Japan Friendship Hospital, Ministry of Health for support for CHNS 2009, Chinese National Human Genome Center at Shanghai since 2009 and Beijing Municipal Center for Disease Prevention and Control since 2011.

Contributors WZ designed this study and revised the manuscript. YL, FX and XY performed data clean, statistical analysis and wrote the first draft of the manuscript, which PL and WH subsequently revised. All authors read the article and approve it for publication.

Funding This study was supported by China's National Development and Reform Commission Grant (No. 2018GFGW001) to WZ.

Competing interests None declared.

Patient and public involvement Patients and/or the public were not involved in the design, or conduct, or reporting or dissemination plans of this research.

Patient consent for publication Not required.

Ethics approval China Health and Nutrition Survey (CHNS) was approved by the ethics committee of Carolina Population Center at the University of North Carolina at Chapel Hill and the NINH at the CCDC. Informed consent was obtained from all subjects before the investigation.

Provenance and peer review Not commissioned; externally peer reviewed.

Data availability statement Data are available in a public, open access repository. Data are available from China Health and Nutrition Survey (https://www.cpc.unc. edu/projects/china/data/).

Open access This is an open access article distributed in accordance with the Creative Commons Attribution Non Commercial (CC BY-NC 4.0) license, which permits others to distribute, remix, adapt, build upon this work non-commercially, and license their derivative works on different terms, provided the original work is properly cited, appropriate credit is given, any changes made indicated, and the use is non-commercial. See: http://creativecommons.org/licenses/by-nc/4.0/.

\section{ORCID iDs}

Yunmei Luo http://orcid.org/0000-0002-2661-3214

Wenzhi Huang http://orcid.org/0000-0002-4074-8422

Wei Zhang http://orcid.org/0000-0003-3113-9577

\section{REFERENCES}

1 GBD 2017 Causes of Death Collaborators. Global, regional, and national age-sex-specific mortality for 282 causes of death in 195 countries and territories, 1980-2017: a systematic analysis for the global burden of disease study 2017. Lancet 2018;392:1736-88.

2 GBD 2017 Risk Factor Collaborators. Global, regional, and national comparative risk assessment of 84 behavioural, environmental and occupational, and metabolic risks or clusters of risks for 195 countries and territories, 1990-2017: a systematic analysis for the global burden of disease study 2017. Lancet 2018;392:1923-94.

3 Lloyd-Jones DM, Larson MG, Leip EP, et al. Lifetime risk for developing congestive heart failure: the Framingham Heart Study. Circulation 2002;106:3068-72.

4 Lewington S, Clarke R, Qizilbash N, et al. Age-specific relevance of usual blood pressure to vascular mortality: a meta-analysis of individual data for one million adults in 61 prospective studies. Lancet 2002;360:1903-13.

5 GBD 2017 DALYs and HALE Collaborators. Global, regional, and national disability-adjusted life-years (DALYs) for 359 diseases and injuries and healthy life expectancy (HALE) for 195 countries and territories, 1990-2017: a systematic analysis for the Global Burden of Disease Study 2017. Lancet 2018;392:1859-922.

6 Liew SJ, Lee JT, Tan CS, et al. Sociodemographic factors in relation to hypertension prevalence, awareness, treatment and control in a multi-ethnic Asian population: a cross-sectional study. BMJ Open 2019;9:e025869.

7 Cho SMJ, Lee H, Kim HC. Differences in prevalence of hypertension subtypes according to the 2018 Korean Society of hypertension and 2017 American College of Cardiology/American heart association guidelines: the Korean National health and nutrition examination survey, 2007-2017 (KNHANES IV-VII). Clin Hypertens 2019;25:26.

8 GBD 2017 Mortality Collaborators. Global, regional, and national age-sex-specific mortality and life expectancy, 1950-2017: a systematic analysis for the Global Burden of Disease Study 2017. Lancet 2018;392:1684-735.

9 Gong P, Liang S, Carlton EJ, et al. Urbanisation and health in China. Lancet 2012;379:843-52.

10 LeBlanc AG, Chaput J-P. Urbanisation and fitness: worrying trends from China. Lancet Child Adolesc Health 2019;3:837-9.

11 Wang Z, Chen Z, Zhang L, et al. Status of hypertension in China: results from the China hypertension survey, 2012-2015. Circulation 2018;137:2344-56.

12 Omran AR. The epidemiologic transition: a theory of the epidemiology of population change. 1971. Milbank $Q$ 2005;83:731-57. 
13 Geiss LS, Wang J, Cheng YJ, et al. Prevalence and incidence trends for diagnosed diabetes among adults aged 20 to 79 years, United States, 1980-2012. JAMA 2014;312:1218-26.

14 Chen Z, Li SN, Wang X, et al. [The incidence of hypertension, overweight, and obesity and relationship with cardiovascular events among middle-aged Chinese: 6 years follow-up results]. Zhonghua Xin Xue Guan Bing Za Zhi 2020;48:47-53.

15 Liang Y, Liu R, Du S, et al. Trends in incidence of hypertension in Chinese adults, 1991-2009: the China Health and Nutrition Survey. Int J Cardiol 2014;175:96-101.

16 Yu X, Xia F, Zhang W. Trends and geographic variations in selfreported diabetes incidence: a prospective open cohort study of Chinese men and women, 1997-2015. Diabet Med 2020:e14447.

17 Zhou M, Wang $\mathrm{H}$, Zeng $\mathrm{X}$, et al. Mortality, morbidity, and risk factors in China and its provinces, 1990-2017: a systematic analysis for the global burden of disease study 2017. Lancet 2019;394:1145-58.

18 Xia F, Yu X, Li Y, et al. Geographic variations of stroke incidence in Chinese communities: an 18-year prospective cohort study from 1997 to 2015. J Stroke 2020;22:345-56.

19 Chen Y, Liang X, Zheng S, et al. Association of body fat mass and fat distribution with the incidence of hypertension in a populationbased Chinese cohort: a 22-year follow-up. J Am Heart Assoc 2018;7:e007153.

20 Sun Z, Zheng L, Zhang X, et al. Ethnic differences in the incidence of hypertension among rural Chinese adults: results from Liaoning Province. PLoS One 2014;9:e86867.

21 Chen X, Liu Y, Sun X, et al. Comparison of body mass index, waist circumference, conicity index, and waist-to-height ratio for predicting incidence of hypertension: the rural Chinese cohort study. $J$ Hum Hypertens 2018;32:228-35.

22 Popkin BM, Du S, Zhai F, et al. Cohort Profile: The China Health and Nutrition Survey--monitoring and understanding socioeconomic and health change in China, 1989-2011. Int J Epidemiol 2010;39:1435-40.

23 Williams B, Mancia G. Ten Commandments of the 2018 ESC/ ESH HTN Guidelines on hypertension in adults. Eur Heart $J$ 2018;39:3007-8.

24 Qi S-F, Zhang B, Wang $\mathrm{H}-\mathrm{J}$, et al. Joint effects of age and body mass index on the incidence of hypertension subtypes in the China Health and Nutrition Survey: a cohort study over 22years. Prev Med 2016;89:23-30.

25 Gao M, Kuang W, Qu P, et al. The time trends of cognitive impairment incidence among older Chinese people in the community: based on the CLHLS cohorts from 1998 to 2014. Age Ageing 2017;46:787-93.

26 Lu J, Lu Y, Wang X, et al. Prevalence, awareness, treatment, and control of hypertension in China: data from 1.7 million adults in a population-based screening study (China PEACE Million Persons Project). Lancet 2017;390:2549-58.

27 Mendonça RdeD, Lopes ACS, Pimenta AM, et al. Ultra-processed food consumption and the incidence of hypertension in a Mediterranean cohort: the Seguimiento Universidad de Navarra Project. Am J Hypertens 2017;30:358-66.

28 Li M, McDermott R. Obesity, albuminuria, and gamma-glutamyl transferase predict incidence of hypertension in Indigenous Australians in rural and remote communities in northern Australia. $J$ Hypertens 2015;33:704-10.

29 Bernabe-Ortiz A, Sanchez JF, Carrillo-Larco RM, et al. Rural-Tourban migration and risk of hypertension: longitudinal results of the PERU MIGRANT study. J Hum Hypertens 2017;31:22-8.

30 Fan W-G, Xie F, Wan Y-R, et al. The impact of changes in population blood pressure on hypertension prevalence and control in China. $J$ Clin Hypertens 2020;22:150-6.
31 He FJ, Li J, Macgregor GA. Effect of longer term modest salt reduction on blood pressure: cochrane systematic review and metaanalysis of randomised trials. BMJ 2013;346:f1325.

32 Gando Y, Sawada SS, Kawakami R, et al. Combined association of cardiorespiratory fitness and family history of hypertension on the incidence of hypertension: a long-term cohort study of Japanese males. Hypertens Res 2018;41:1063-9.

33 Bo Y, Guo C, Lin C, et al. Dynamic changes in long-term exposure to ambient particulate matter and incidence of hypertension in adults. Hypertension 2019;74:669-77.

34 Trudel X, Brisson C, Gilbert-Ouimet M, et al. Long working hours and the prevalence of masked and sustained hypertension. Hypertension 2020;75:532-8

35 Li J, Shi L, Li S, et al. Urban-rural disparities in hypertension prevalence, detection, and medication use among Chinese adults from 1993 to 2011. Int J Equity Health 2017;16:50.

$36 \mathrm{Yu}$ X, Zhang W. All-cause mortality rate in China: do residents in economically developed regions have better health? Int J Equity Health 2020;19:12.

37 Arici M, Turgan C, Altun B, et al. Hypertension incidence in Turkey (HinT): a population-based study. J Hypertens 2010;28:240-4.

38 Feng XL, Pang M, Beard J. Health system strengthening and hypertension awareness, treatment and control: data from the China Health and Retirement Longitudinal Study. Bull World Health Organ 2014;92:29-41

39 Kim BJ, Seo DC, Kim BS, et al. Relationship between cotinineverified smoking status and incidence of hypertension in 74,743 Korean adults. Circ J 2018;82:1659-65.

40 Gao K, Shi X, Wang W. The life-course impact of smoking on hypertension, myocardial infarction and respiratory diseases. Sci Rep 2017;7:4330.

$41 \mathrm{Li} \mathrm{G}$, Wang $\mathrm{H}$, Wang $\mathrm{K}$, et al. The association between smoking and blood pressure in men: a cross-sectional study. BMC Public Health 2017;17:797.

42 Kim Y, Sharp S, Hwang S, et al. Exercise and incidence of myocardial infarction, stroke, hypertension, type 2 diabetes and site-specific cancers: prospective cohort study of 257854 adults in South Korea. BMJ Open 2019;9:e025590.

43 Lu Y, Lu M, Dai H, et al. Lifestyle and risk of hypertension: follow-up of a young pre-hypertensive cohort. Int J Med Sci 2015;12:605-12.

44 Jayawardana NWIA, Jayalath WATA, Madhujith WMT, et al. Aging and obesity are associated with undiagnosed hypertension in a cohort of males in the Central Province of Sri Lanka: a cross-sectional descriptive study. BMC Cardiovasc Disord 2017;17:165.

45 Sinnott S-J, Smeeth L, Williamson E, et al. Trends for prevalence and incidence of resistant hypertension: population based cohort study in the UK 1995-2015. BMJ 2017;358:j3984.

46 Zhou W, Shi Y, Li Y-Q, et al. Body mass index, abdominal fatness, and hypertension incidence: a dose-response meta-analysis of prospective studies. J Hum Hypertens 2018;32:321-33.

47 Roerecke M, Kaczorowski J, Tobe SW, et al. The effect of a reduction in alcohol consumption on blood pressure: a systematic review and meta-analysis. Lancet Public Health 2017;2:S2468-2667(17)300038:e108-20

48 Whelton PK, Carey RM, Aronow WS, et al. 2017 ACC/AHA/AAPA/ ABC/ACPM/AGS/APhA/ASH/ASPC/NMA/PCNA guideline for the prevention, detection, evaluation, and management of high blood pressure in adults: Executive summary: a report of the American College of Cardiology/American heart association Task force on clinical practice guidelines. Circulation 2018;138:CIR.00000000000 00597:e426-83.

49 Holmes MV, Dale CE, Zuccolo L, et al. Association between alcohol and cardiovascular disease: Mendelian randomisation analysis based on individual participant data. BMJ 2014;349:g4164. 